\title{
Early and late fawn mortality in a remnant population of Arabian gazelles (Gazella arabica)
}

\author{
Benny Shalmon ${ }^{1} \cdot$ Ping Sun ${ }^{2} \cdot$ Torsten Wronski ${ }^{3}$ (I)
}

Received: 28 June 2020 / Accepted: 13 July 2021 / Published online: 28 July 2021

(c) The Author(s) 2021

\begin{abstract}
The Arabian gazelle (Gazella arabica) population in Israel has experienced a turbulent conservation history and repeatedly faced local extinction. Low fawn survival was considered the main cause for the constant decline. In our study, we analyzed instantaneous fawn mortality rates, using a binomial coding at three different developmental stages, i.e., mortality rates to 3 months after parturition (weaning age), to 5 months after parturition (male fawns leave their mothers), and to the age of reproductive maturity, i.e., recruitment (12 months). We used a dataset obtained from 20 individually discernible mothers and their fawns (49 females and 48 males) born between June 2006 and September 2019. To explore causes for the fawn mortality rates, parental- (age of the mother at parturition) and offspring-related attributes (offspring sex), year of birth, together with one weather variable (mean monthly maximum temperature) were included as independent variables into three independent mixed effects cox regression models. Out of 97 fawns, 92 survived to weaning age, 73 to the age of 5 months and only 7 to the age of reproductive maturity. Temperature had significant effects on instantaneous fawn mortality rates, suggesting that low temperatures were detrimental to the survival of fawns after weaning (4-5 months) and male dispersal age (6-12 months). Male offspring encountered a higher instantaneous mortality rate than female offspring at the age of 6-12 months. Moreover, fawns from less experienced mother (young age at parturition) experienced higher mortality. Our results were in line with previous studies on fawn mortality observed in other desert dwelling ungulates.
\end{abstract}

Keywords Instantaneous mortality rate $\cdot$ Weaning age $\cdot$ Reproductive maturity $\cdot$ Mother's experience $\cdot$ Offspring sex Weather conditions

The scientific monitoring of population dynamics plays a vital role in wildlife management, particularly for threatened and endangered desert ungulates. Recruitment (including immigration), dispersal (emigration) and mortality due to ecological stressors (e.g., climate, resource availability, predation, or parasites) are the main drivers shaping the size of a population. Population recruitment is determined by the

Handling editor: Heiko G. Rödel.

Torsten Wronski

t_wronski@gmx.de

Israel Nature and Parks Authority (INPA), Eilat, Israel

2 Faculty of Forest and Environment, Eberswalde University for Sustainable Development, Schicklerstraße 5, 16225 Eberswalde, Germany

3 School of Biological and Environmental Sciences, Faculty of Science, Liverpool John Moores University, Byrom Street, Liverpool L3 3AF, UK number of adult individuals immigrating into the population and - to a much largely extent - by the number and survival of new-born (Gaillard et al. 2008; Willis 2011). Parental attributes such as the mother's experience (age at parturition), the amount of parental care (maternal provisioning) or the genetic quality of the parents play an important role during early life stages, but also offspring-related attributes such as the sex or weight at birth (Clutton-Brock et al. 1982; Alados and Escos 1991). Among environmental factors, unfavorable weather conditions, such as low precipitation or low temperatures, can have detrimental effects on the survival of the new-born (e.g., Clutton-Brock et al. 1985; Johnstone-Yellin et al. 2009).

Effective conservation of threatened and endangered species requires identifying the main driver(s) of population decline (Caughley 1994). In recent decades, populations of Arabian gazelles were declining within their native range along the coastal plains and mountain ridges of the Arabian Peninsula (Thouless et al. 1991, 1997; Mallon 
and Kingswood 2001; Strauss et al. 2009; Lerp et al. 2014; Al Hikmani et al. 2015; Al Jahdhami et al. 2017). These declines have prompted the IUCN Red list to classify the species as vulnerable (C2a,i; IUCN/SSC Antelope Specialist Group 2017). Within Israel, a subspecies of the Arabian gazelle (G. a. acaciae, Mendelssohn et al. 1997) was ranked as 'critically endangered' since only a tiny population of 15-50 individuals survives in the Yotvata Nature Reserve, located in the southern Arava Valley $\left(29^{\circ} 52^{\prime} 43.5^{\prime \prime} \mathrm{N}\right.$, $35^{\circ} 2^{\prime} 21.2^{\prime \prime}$; Dolev and Perevolotsky 2004). Despite this population being protected from illegal hunting since 1955 (Clark and Frankenberg 2001), it has undergone a turbulent conservation history and has repeatedly faced local extinction (King et al. 1993; Blank 1996, 2000, 2005). Several causes were proposed for the decline, including carnivore predation (mainly wolf, Canis lupus and golden jackal, Canis aureus; Shalmon et al. 2020), competition with sympatric dorcas gazelles (Gazella dorcas; Breslau et al. 2019), inbreeding (Hadas et al. 2015) and climate change (Dolev and Perevolotsky 2004). Since 1965-the year when regular counts were introduced by the Israel Nature and Park Authority (INPA) - the population size experienced periodic undulations apparently related to the occurrence of wolves (Shalmon et al. 2020). Despite a considerable conservation effort and resource input by the INPA (i.e., predator culling, artificial water and food supply, irrigation, enclosure construction), the overall population trend continues to show a decline. In this study, we evaluated how two other factors potentially influencing population decline of Arabian gazelles - mothers experience and weather-affected juvenile recruitment, a demographic rate known to have high influence on ungulate population dynamics (Gaillard et al. 2000).

Monitoring the long-term reproductive success of females as well as the survival of their fawns is pivotal to understand the success (or failure) of the G. arabica conservation program in Israel. In their study on factors driving the Arabian gazelle in Israel to extinction, Shalmon et al. (2020) used time series analysis to investigate population size and fawn survival in relation to the occurrence of wolves in the prime habitat of the gazelles. Their study suggested a strong impact of wolf predation on the gazelle population and a moderate effect of climate on fawn mortality, while competition and resource availability played only a minor role (but see Breslau et al. 2019). In our present study, we made use of a unique dataset, obtained from arbitrary sightings of 20 individually discernible mothers and their fawns (49 females and 48 males). Individuals were distinguished by the shape of their horns, face markings, or other characteristics such as scares and ear-cuts (Shalmon unpubl. data). All fawns were born from 5 June 2006 to 20 September 2019, a period when the population was protected from wolf predation by a fenced enclosure (3.5 km² ; Shalmon et al. 2020). Given that the enclosure protected the gazelles effectively from carnivore predation (data obtained during a period when the fence was collapsed were excluded from our analysis), we therefore rejected the probability that the high fawn mortality was due to predation (or indirect effects of predation such as stress, or trauma after hitting the fence). In their study, Shalmon et al. (2020) investigated the fawn survival of $G$. arabica to the age of five months. In this study, we expanded our data set, also including the fawn survival to weaning age (3 months) and to reproductive maturity (12 months). While Shalmon et al. (2020) referred to an annual cycle, this study focused on monthly instantaneous fawn mortality rates using the life history data of 20 mothers and their fawns and relating them to monthly weather data that directly followed each birth. Moreover, the Arabian gazelle population (with a population density of 4.3-15.7 individuals $/ \mathrm{km}^{2}$ during the study period) were accompanied by $83-181$ dorcas gazelles (density: $23.7-51.7$ individuals $/ \mathrm{km}^{2}$ ), causing some competition for food resources but with no significant effect on the survival of G. arabica fawns (Shalmon et al. 2020). Consequently, we did not include competition with dorcas gazelles (i.e., G. dorcas population size) into our analysis.

The central question of our current study was the high fawn mortality experienced by the Arava population since monitoring began in 1964 (Shalmon 1989, 1991; Yom-Tov 2016; Shalmon et al. 2020). We analyzed the instantaneous fawn mortality rates at three different developmental stages: (i) within the first three months after parturition (i.e., weaning age; Mendelssohn et al. 1995), (ii) between the age of four and five months (i.e., the time male fawns leave their mothers; Shalmon 1991; Shalmon and Wronski 2021), and (iii) to recruitment age, i.e., the age of reproductive maturity (6-12 months; Habibi 1991; Mendelssohn et al. 1995). To explore causes for the high offspring mortality, we tested a parental attribute (age of the mother at parturition), an offspring-related attribute (offspring sex), year of birth and one weather variable (mean monthly maximum temperature) obtained from WorldClim at 2.5-min resolution (Hijmans et al. 2005). Initially, we included precipitation as a second weather variable but due to a strong collinearity with mean monthly maximum temperature, we refrained from doing so. Temperature data were accumulated and averaged, for a period of 0 to 3 months, for 4 to 5 months and for 6 to 12 months after parturition. Subsequently, all covariates were standardized to obtain one unit. The above attributes as well as two interaction terms (i.e., mean monthly maximum temperature $\times$ month of death, and offspring sex $\times$ mean monthly maximum temperature) were included as independent variables, while mother ID was used as a random factor in three independent mixed effects cox regression models (fit by maximum likelihood), using the R package 'coxme' (Therneau 2012). The model selection process was based on Akaike Information Criteria (AIC) and the best fit model, 
with the lowest AIC, was determined (Online Resources 1). Inspection of model residuals did not indicate violations of model assumptions.

Out of a total of 97 fawns, only 4 females $(8.2 \%)$ and 1 male $(2.1 \%)$ deceased before weaning age (Fig. 1). The mixed effects cox regression null model was selected as the best fit (Table 1). Hereby, neither the independent variables, nor their interaction terms had any significant effect on instantaneous fawn mortality rate. Another 11 females $(30.6 \%)$ and 8 males $(18.8 \%)$ died prior to the age of 5 months (Fig. 1). The best mixed effects cox regression model included temperature and the interaction temperature $\times$ month of death as explanatory variables. Temperature had a significant negative effect on the instantaneous fawn mortality rate at this developmental stage (Table 1), indicating low temperatures were detrimental to fawn survival during the male dispersal stage. A total of 30 females (91.8\%) and 36 males $(93.8 \%)$ died before reaching the age of reproductive maturity (recruitment age, Fig. 1). For this developmental stage, the best mixed effects cox regression model included offspring sex, age of the mother at parturition, temperature, and two interaction terms (temperature $\times$ month of death, temperature $\times$ offspring sex) as explanatory variables (Table 1). The age of the mother at parturition had a significant, negative effect on the instantaneous fawn mortality rate (Table 1), suggesting that fawns from less experienced mothers faced higher mortalities than fawns from experienced mothers. This result was not surprising since numerous
Fig. 1 Cumulative mortality (number of individuals; left $\mathrm{x}$-axis) and mean monthly maximum temperature (right $\mathrm{x}$-axis, gray bars) over a period of 16 months after parturition for male and female Gazella arabica fawns (shaded and black curves respectively) born in the Yotvata NR from June 2006 to September

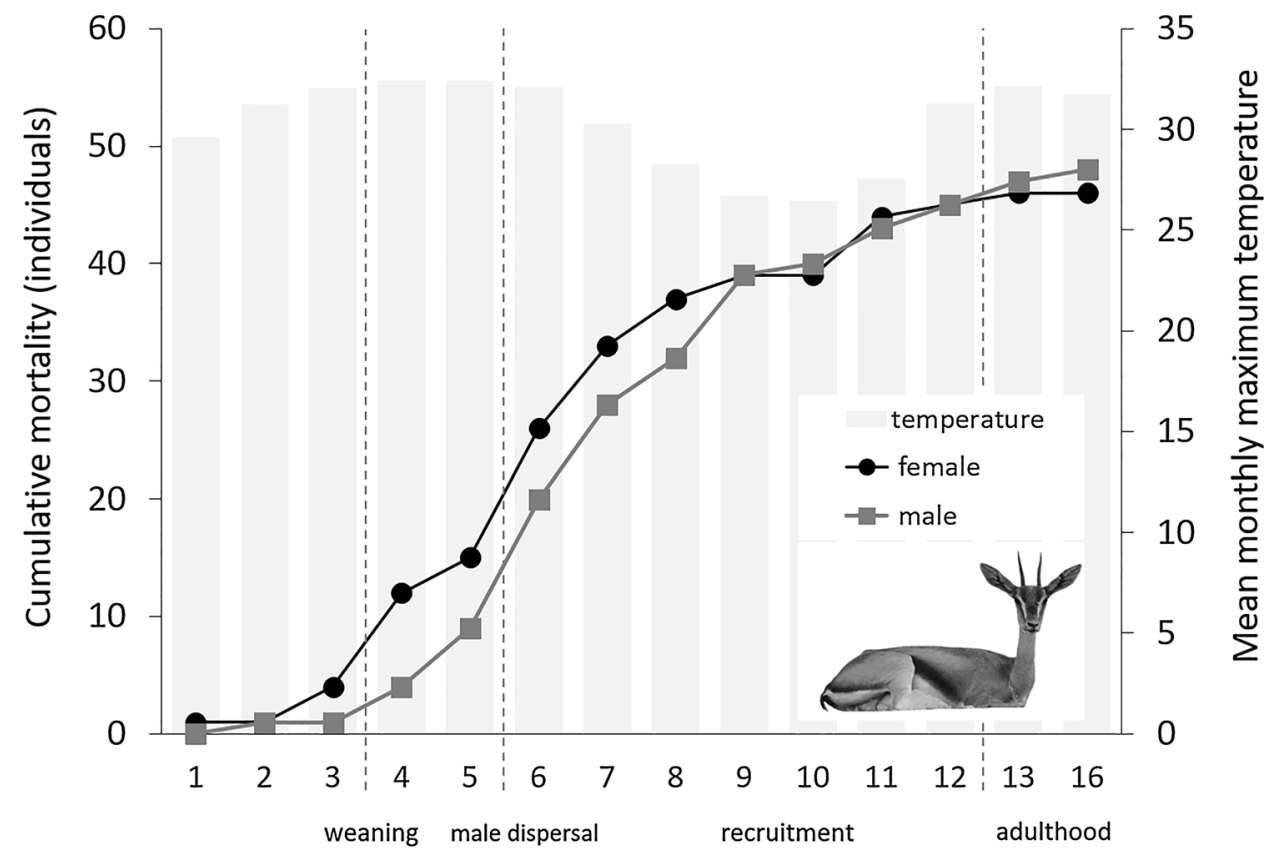

Months after parturition
Table 1 Best fit mixed effects cox regression models (ranked by AIC) examining the Gazella arabica instantaneous fawn mortality rate at three developmental stages (to weaning age: 0 to 3 months, to male dispersal: $4-5$ months, and to recruitment: 6-12 months after parturition)

\begin{tabular}{lllll}
\hline Models & $\begin{array}{l}\text { Hazard } \\
\text { ratio=exp } \\
\text { (coefficient) }\end{array}$ & SE (coefficient) & $Z$ & \\
& & & & \\
\hline Mortality rate (0-3 months) & - & - & - \\
$\quad$ Null model & & & & \\
Mortality rate (4-5 months) & 0.625 & 0.216 & $-2.170 \quad \mathbf{0 . 0 3 0}$ \\
$\quad$ Mean monthly max. temperature & & & & \\
Mortality rate (6-12 months) & 1.146 & 0.268 & 0.510 & 0.610 \\
Offspring sex & 0.766 & 0.134 & -1.991 & $\mathbf{0 . 0 4 7}$ \\
Mother's age at parturition & 0.162 & 0.517 & -3.520 & $<\mathbf{0 . 0 0 1}$ \\
Mean monthly max. temperature & 1.148 & 0.044 & 3.160 & $\mathbf{0 . 0 0 2}$ \\
Mean monthly max. temperature $\times$ month of death & & & & \\
Offspring sex $\times$ Mean monthly max. temperature & 3.190 & 0.302 & 3.840 & $<\mathbf{0 . 0 0 1}$ \\
\hline
\end{tabular}

Models were fit by maximum likelihood. Significant effects $(p<0.05)$ are given in bold 
studies reported parental age to have short- and long-term effects on the life history traits of offspring including longevity, fecundity, and survival (e.g., Carnes et al. 2012; Ducatez et al. 2012).

Moreover, low temperatures were also significantly correlated to high instantaneous mortality rates at the recruitment age, a result which was supported by two positive interaction effects, i.e., mean monthly maximum temperature $\times$ month of death, and offspring sex $\times$ mean monthly maximum temperature on the mortality (Table 1; Fig. 1), indicating that low temperatures are disadvantageous to fawn survival, especially for male fawns at this developmental stage. This result is in line with findings from a captive population of Arabian gazelles on the Arabian Peninsula, which found respiratory infection to be a major cause of mortality, accounting for $15.3 \%$ of juvenile deaths, most prevalent during the winter season (November to March) when night temperatures are often below $0{ }^{\circ} \mathrm{C}$ and humidity is high (Soares et al. 2015). Moreover, several previous studies on gazelles (e.g., Alados and Escos 1991; Riesch et al. 2013; Martin et al. unpubl. data), found the mortality rate of female fawns to be lower than that of male fawns, probably as a consequence of faster growth rates, increased metabolic rates and thus larger nutritional requirements and reduced fat reserves, and (Clutton-Brock et al. 1985). In all three models, the mortality rate was not affected by the year of birth. The random effect of mother ID explained less than $1 \%$ of the models' variance during the recruitment period, but $45.0 \%$ of the model's variance prior to male dispersal. Thus, pedigree had a significant effect on the mortality rates of fawns after weaning, suggesting that differences in postnatal maternal investment play a major role. This is in line with results reported by Riesch et al. (2015) who found mother ID to be important in explaining model variance at least to weaning age. After weaning, i.e., the time when fawns become independent from postnatal maternal care, this maternal effect strongly decreased and eventually disappeared.

During the first three months after parturition $8.2 \%$ of females and $2.1 \%$ of males died. Prior to male dispersal age another $30.6 \%$ of females and $18.8 \%$ of males died, while $91.8 \%$ of females and $93.8 \%$ of males deceased before reaching reproductive maturity (Fig. 1). The mortality rate to three months is similar to that reported from other desert dwelling gazelles (e.g., G. cuvieri: 16\%, Nanger dama: 27-33\%, Alados and Escos 1991; G. marica: $13-16 \%$, Riesch et al. 2013), but fawn mortality before reaching recruitment age was alarmingly high compared to other species (e.g., G. gazella: 26-58\%, Baharav 1983a, b; G. marica: $15-20 \%$, Riesch et al. 2013). Most of the mortalities occurred after weaning (or after male fawns had left their mothers), i.e., the time when fawns were required to look for their own solid food (mainly the leaves, flowers and pods of Vachellia [formerly Acacia] raddiana and $V$. tortilis). Given that most births occur in spring (March to May; Shalmon 1991; Yom-Tov 2016), this usually happens during the hot summer months (July-September) when Vachellia leaf availability is decreasing (no green leaves at browsing height; Breslau et al. 2019) and gazelles entirely rely on highly nutritious Vachellia pods and flowers fallen onto the ground (Halevy and Orshan 1973; Wronski and Schulz-Kornas 2015). Further into autumn, this sort of fodder becomes scarcer and from December onwards hardly any Vachellia food items remain (Halevy and Orshan 1973). This food shortage, paired with low temperatures and high humidity-leading to increased rates of respiratory diseases-may thus explain the high fawn mortality observed during the recruitment period.

It was also speculated that inbreeding might be a cause for the high fawn mortality in this population (Shalmon 1991; Hadas et al. 2015; Shalmon and Wronski 2021). Inbreeding was described for several captive gazelle populations, including G. dorcas, G. cuvieri, Nanger dama (Ralls et al. 1980; Ballou and Ralls 1982) and G. spekei (Kalinowski et al. 2001). Experiences from captive gazelle populations revealed that fawns born by inbred mothers usually die within the first 6 months after parturition, with the highest likelihood during the first four weeks (Ralls et al. 1979, 1980; Ballou and Ralls 1982; Kalinowski et al. 2001). In the Yotvata NR, most fawns died after the age of three months (Fig. 1), suggesting that deleterious effects of inbreeding are unlikely to be the reason for the high fawn mortality reported from the reserve.

Supplementary Information The online version contains supplementary material available at https://doi.org/10.1007/s42991-021-00162-x.

Acknowledgements We would like to explicitly thank David Blank for his considerable efforts to save G. arabica acaciae from local extinctions and for the information he contributed to this article.

Author contributions BS: field work and data collection; PS: statistical analysis; TW: manuscript preparation.

Funding The study was financially supported by the Society for the Protection of Nature in Israel (SPNI) and the Israel Nature and Parks Authority (INPA).

\section{Declarations}

Conflict of interest All authors declare no conflict of interest.

Ethical approval No human participants. The study was initiated and conducted by the Israel Nature and Parks Authority (INPA). Ethical approval was therefore not needed.

Informed consent All authors declare to have participated in this study.

Consent for publication All authors agree on the publication of the data and results presented in this article. 
Open Access This article is licensed under a Creative Commons Attribution 4.0 International License, which permits use, sharing, adaptation, distribution and reproduction in any medium or format, as long as you give appropriate credit to the original author(s) and the source, provide a link to the Creative Commons licence, and indicate if changes were made. The images or other third party material in this article are included in the article's Creative Commons licence, unless indicated otherwise in a credit line to the material. If material is not included in the article's Creative Commons licence and your intended use is not permitted by statutory regulation or exceeds the permitted use, you will need to obtain permission directly from the copyright holder. To view a copy of this licence, visit http://creativecommons.org/licenses/by/4.0/.

\section{References}

Al Hikmani H, Zabanoot S, Al Shahari T, Zabanoot N, Al Hikmani K, Spalton A (2015) Status of Arabian gazelle, Gazella arabica (Mammalia, Bovidae) in Dhofar, Oman. Zool Middle East 61:295-299. https://doi.org/10.1080/09397140.2015.1101905

Al Jahdhami MH, Al Bulushi S, Al Rawahi H, Al Fazari W, Al Amri A, Al Owaisi A, Al Rubaiey S, Al Abdulasalam Z, Al Ghafri M, Yadav S, Ross S (2017) The status of Arabian gazelles Gazella arabica in Al Wusta Wildlife Reserve and Ras Ash Shajar Nature Reserve, Oman. JoTT 9:10369-10373. https://doi.org/10.11609/ jott.3398.9.7.10369-10373

Alados CL, Escos J (1991) Phenotypic and genetic characteristics affecting lifetime reproductive success in female Cuvier's, dama and dorcas gazelles (Gazella cuvieri, G. dama and G. dorcas). J Zool Lond 223:307-321. https://doi.org/10.1111/j.1469-7998. 1991.tb04767.x

Baharav D (1983) Reproductive strategies in female mountain and dorcas gazelles (Gazella gazella gazella and Gazella dorcas). $\mathrm{J}$ Zool Lond 200:445-453. https://doi.org/10.1111/j.1469-7998. 1983.tb02808.x

Baharav D (1983) Observations on the ecology of the mountain gazelle in the Upper Galilee, Israel. Mammalia 47:59-69. https://doi.org/ 10.1515/mamm.1983.47.1.59

Ballou J, Ralls K (1982) Inbreeding and juvenile mortality in small populations of ungulates: a detailed analysis. Biol Conserv 24:239-272. https://doi.org/10.1016/0006-3207(82)90014-3

Blank DA (1996) The Acacia gazelle: extinction of a subspecies. Gnusletter 15:7-9

Blank DA (2000) Acacia gazelle increases with habitat improvement. Gnusletter 19:11-13

Blank DA (2005) Sunset of the Acacia Gazelle. Gnusletter 24:6-7

Breslau B, Polak T, Shalmon B, Groner E (2019) Evidence of browsing pressure on the critically endangered Acacia gazelle (Gazella acaciae). J Arid Environ 173:e104019. https://doi.org/10.1016/j. jaridenv.2019.104019

Carnes BA, Riesch R, Schlupp I (2012) The delayed impact of parental age on offspring mortality in mice. J Gerontol A Biol Sci Med Sci 67A:351-357

Caughley G (1994) Directions in conservation biology. J Anim Ecol 63:215-244

Clark B, Frankenberg E (2001) Israel (including West Bank and Gaza). In: Mallon DP, Kingswood SC (eds) Antelopes, Part 4: North Africa, the Middle East, and Asia-Global Survey and Regional Action Plans. IUCN/SSC, Gland, pp 107-111

Clutton-Brock TH, Guinness FE, Albon SD (1982) Red deer behavior and ecology of two sexes. Edinburgh University Press, Edinburgh

Clutton-Brock TH, Albon SD, Guinness FE (1985) Parental investment and sex differences in juvenile mortality in birds and mammals. Nature 313:131-133. https://doi.org/10.1038/313131a0
Dolev A, Perevolotsky A (2004) The Red Book: vertebrates in Israel. Israel Nature and Parks Authority and Society for the Protection of Nature in Israel, Tel Aviv

Ducatez S, Baguette M, Stevens VM, Legrand D, Fréville H (2012) Complex interactions between paternal and maternal effects: parental experience and age at reproduction affect fecundity and offspring performance in a butterfly. Evolution 66:3558-3569

Gaillard J-M, Festa-Bianchet M, Yoccoz NG, Loison A, Toïgo C (2000) Temporal variation in fitness components and population dynamics of large herbivores. Annu Rev Ecol Evol Syst 31:367-393

Gaillard J-M, Coulson T, Festa-Bianchet M (2008) Recruitment. In: Jørgensen SE, Fath BD (eds) Encyclopedia of ecology. Elsevier, Amsterdam, pp 2982-2986

Habibi K (1991) Arabian gazelles. National Commission for Wildlife Conservation and Development, Riyadh

Hadas L, Hermon D, Boldo A, Arieli G, Gafny R, King R, Kahila BarGal G (2015) Wild gazelles of the southern Levant: genetic profiling defines new conservation priorities. PLoS ONE 10:e0116401. https://doi.org/10.1371/journal.pone.0116401

Halevy G, Orshan G (1973) Ecological studies on Acacia species in the Negev and Sinai. II. Phenology of Acacia raddiana, A. tortilis and A. gerradii ssp. negevensis. Isr J Bot 22:120-138

Hijmans RJ, Cameron SE, Parra JL, Jones PG, Jarvis A (2005) Very high resolution interpolated climate surfaces for global land areas. Int J Climatol 25:1965-1978

IUCN SSC Antelope Specialist Group (2017) Gazella arabica. The IUCN Red List of Threatened Species 2017, e.T117582065A88018124

Johnstone-Yellin TL, Shipley LA, Myers WL, Robinson HS (2009) To twin or not to twin? Trade-offs in litter size and fawn survival in mule deer. J Mammal 90:453-460. https://doi.org/10.1644/ 08-MAMM-A-030.1

Kalinowski ST, Hedrick PW, Miller PS (2001) Inbreeding depression in the Speke's gazelle captive breeding program. Conserv Biol 14:1375-1384

King R, Saltz D, Shalmon B (1993) Gazella Gazella in Southern Israel. Gnusletter 12:12

Lerp H, Plath M, Wronski T, Malczyk A, Riesch RR, Streit B, Pfenninger M (2014) Utility of island populations in reintroduction programs-relationships between Arabian gazelles (Gazella arabica) from the Farasan Archipelago and endangered mainland populations. Mol Ecol 23:1910-1922. https://doi.org/10.1111/ mec. 12694

Mallon DP, Kingswood SP (2001) Antelopes. Part IV. North Africa, the Middle East and Asia Global survey and regional action plans. IUCN/SSC, Gland and Cambridge

Mendelssohn H, Yom-Tov Y, Groves CP (1995) Gazella Gazella. Mamm Species 490:1-7. https://doi.org/10.2307/0.490.1

Mendelssohn H, Groves CP, Shalmon B (1997) A new subspecies of Gazella gazella from the southern Negev. Isr J Zool 43:209-215. https://doi.org/10.1080/00212210.1997.10688905

Ralls K, Brugger K, Ballou J (1979) Inbreeding and juvenile mortality in small populations of ungulates. Science 206:1101-1103. https://doi.org/10.1126/science.493997

Ralls K, Brugger K, Glick A (1980) Deleterious effects of inbreeding in a herd of captive dorcas gazelle. Int Zoo Yearb 20:137-146. https://doi.org/10.1111/j.1748-1090.1980.tb00957.x

Riesch R, Martin RA, Lerp H, Plath M, Wronski T (2013) Size and sex matter: reproductive biology and determinants of offspring survival in Gazella marica. Biol J Linn Soc 110:116-127. https:// doi.org/10.1111/bij.12121

Shalmon B (1989) The ecology of Gazella gazella spp. in the southern Arava valley. Isr J Zool 35:97

Shalmon B (1991) Excerpt of conservation program for the gazelle Gazella gazella acaciae. Gnusletter 10:10-11 
Shalmon B, Wronski T (2021) The conservation history of Arabian gazelles (Gazella arabica) in Israel-do fifty-five years monitoring help to define future incentives. In: Hung SW (ed) Animal science. MedDocs Publishers, Reno, pp 21-38

Shalmon B, Sun P, Wronski T (2020) Factors driving Arabian gazelles (Gazella arabica) in Israel to extinction-time series analysis of population size and juvenile survival in an unexploited population. Biodivers Conserv 29:315-332. https://doi.org/10.1007/ s10531-019-01884-8

Soares JF, Pereira H, Desta FS, Sandouka M, Macasero W (2015) Causes of mortality of captive Arabian gazelles Gazella arabica at King Khalid Wildlife Research Centre, Kingdom of Saudi Arabia, from 1988 to 2011. J Zoo Wildl Med 46:1-8

Strauss M, Al Kharousi Y, Spalton A (2009) Status of the mountain gazelle population in the Arabian Oryx Sanctuary of Oman. Wildl Middle East News 3:5

Therneau T (2012) coxme: mixed effects cox models. R package version 2.2-3. http://CRAN.R589project.org/package $=$ coxme

Thouless CR, Grainger JG, Shobrak M, Habibi K (1991) Conservation status of gazelles in Saudi Arabia. Biol Conserv 58:85-98. https:// doi.org/10.1016/0006-3207(91)90046-C
Thouless CR, Habibi K, Magin C, Wacher T (1997) Status and distribution of gazelles in Saudi Arabia. In: Habibi K, AbuZinada A, Nader I (eds) The gazelles of Arabia. National Commission for Wildlife Conservation and Development, Riyadh, pp 52-67

Willis J (2011) Modelling swimming aquatic animals in hydrodynamic models. Ecol Model 222:3869-3887. https://doi.org/10.1016/j. ecolmodel.2011.10.004

Wronski T, Schulz-Kornas E (2015) The Farasan gazelle-a frugivorous browser in an arid environment. Mamm Biol 80:87-95. https://doi.org/10.1016/j.mambio.2014.12.002

Yom-Tov Y (2016) Gazelles in Israel. Dan Peri Press, Tel Aviv

Publisher's Note Springer Nature remains neutral with regard to jurisdictional claims in published maps and institutional affiliations. 